\title{
DESENVOLVIMENTO DE REBOLO USADO NA RETIFICAÇÃO DE CILINDROS DE TRABALHO EM FERRO FUNDIDO NODULAR INDEFINIDO NA LAMINAÇÃO DE TIRAS A QUENTE*
}

\section{Resumo}

Adilson Rodrigues da Costa ${ }^{1}$ Danilo Deon do Nascimento ${ }^{2}$ Gladston Santos Ferreira Silva ${ }^{3}$ José Herbert Dolabela da Sllveira Luciano Alves Novelli 5 Roberto Sabino Soares ${ }^{6}$ Willy Schuwarten Junior ${ }^{7}$

Os cilindros usados em laminadores a quente, especialmente os cilindros de trabalho são submetidos a altas taxas de desgaste da superfície durante a laminação. Após a campanha de laminação os cilindros devem ser enviados para uma retifica de cilindros para remover a camada danificada. Para este processo de retifica, são utilizadas rebolos com alta eficiência de corte e alta resistência. $O$ objetivo foi analisar os resíduos metálicos e as partículas abrasivas do rebolo após a retificação dos cilindros e, correlacionar com o desempenho obtido com dois tipos diferentes de rebolos, sendo assim capaz de definir um rebolo com melhor desempenho e menor custo operacional.

Palavras-chave: Cilindros; Rebolos; Partículas abrasivas; Desgaste.

\section{DEVELOPMENT OF GRINDING WHEEL USED FOR GRINDING THE WORK ROLL IN NODULAR CAST IRON INDEFINITE IN HOT STRIP ROLLING MILLS}

\begin{abstract}
The rolls used in hot rolling mills, especially the work rolls are subjected to high rates of surface wear during rolling. After the rolling campaign of rolls, they should be sent to a grinding wheel to remove the damaged layer. For this grinding process, are used grinding wheels with high cutting efficiency and resistance. The objective was to analyze the metallic and residue of abrasive particles of the grinding wheel after grinding of rolls and correlate with the performance obtained with two different types of grinding wheels, thus being able to define a grinding wheel for better performance and lower operating cost.
\end{abstract}

Keywords: Rolls; Grinding wheel; Abrasives particle; Wear.

1 Engenheiro Metalurgista, D.Sc., Professor da Universidade Federal de Ouro Preto. MG, Brasil.

2 Engenheiro de Produção, MBA gestão de Projetos, Chefe de Operação, Oficina de Cilindros da Laminação de Tiras a Quente, Gerdau, Brasil.

3 Técnico em Mecânica, Técnico de Cilindros, Oficina de Cilindros da Laminação de Tiras a Quente, Gerdau, Brasil.

4 Sócio da ABM, Engenheiro Metalurgista, M.Eng., M.B.A, Gerente, Laminação de Chapas Grossas, Gerdau, Brasil.

5 Engenheiro Metalurgista e de Materiais, MSc., Facilitador de Melhoria da Oficina de Cilindros, Gerdau Usina Ouro Branco, MG, Brasil.

6 Técnico Mecânico - Facilitador de Melhoria da Oficina de Cilindros - Gerdau Usina Ouro Branco. MG, Brasil.

7 Sócio da ABM, Engenheiro Mecânico, M.Eng., Gerente da Laminação de Tiras a Quente, Gerdau, Brasil.

* Contribuição técnica ao $51^{\circ}$ Seminário de Laminação - Processos e Produtos Laminados e Revestidos, 28 a 31 de outubro de 2014, Foz do Iguaçu, PR, Brasil. 


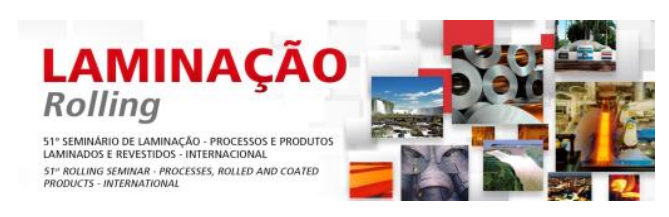

\section{INTRODUÇÃO}

O processo evolutivo para a obtenção de bobinas de aço de tiras a quente utiliza em suas cadeiras cilindros que estão em contato direto com a superfície da chapa durante o processo de laminação. Estes cilindros são conhecidos por cilindros de trabalho. Os cilindros de trabalho são responsáveis pela deformação da placa de aço transformando-a numa bobina, e esta operação é submetida a um sistema de tribológico muito complexo de desgaste da superfície. O foco principal é o estudo do desgaste abrasivo. São tradicionalmente aceito quatro modos de desgaste que são mostrados na figura 1 [1].

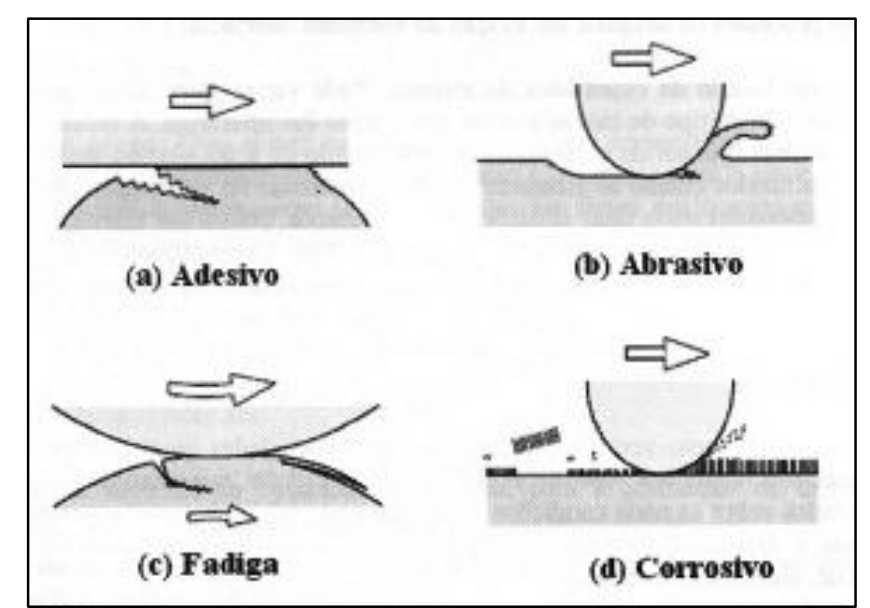

Figura 1 - Representação dos quatros tipos principais de desgaste.

A degradação da superfície do cilindro ou da superfície desgastada gerada durante a laminação deve ser removida na unidade de retificação de cilindros conforme figura 2a.

Em termos de cilindros para laminação, há muitas qualidades e, no caso da aplicação de cilindros de trabalho em unidades de laminação de produtos planos uma das primeiras especificações é em ferro fundido nodular qualidade fabricada pelo processo de dupla fusão com camada indefinida ou mais conhecido como ICDP.

O rebolo (ver Figura 2b) é a ferramenta abrasiva de retificação, o qual é responsável por garantir o retorno da qualidade superficial dos cilindros. Nesta operação, os passes de desbaste e acabamento irão conseguir eliminar os defeitos superficiais e, garantir uma rugosidade definida. O rebolo é composto por partículas abrasivas ligadas por um elemento ligante. O processo de remoção de material metálico é por desgaste abrasivo a dois corpos e, as partículas abrasivas do rebolo têm arestas e elevada dureza, garantindo a eficiência do processo de retifica [2].

No processo de retifica, os rebolos que, são peças cilíndricas, trabalham durante toda a sua operação com um fluido lubrificante que, é o elemento responsável por controlar a temperatura do processo, ter efeito de lubrificação e de remoção de cavacos.

Desta forma, foi possível definir como um sistema tribológico, o processo de retifica que se resume a: os parâmetros do processo de retifica (velocidade do rebolo, deslocamento, inclinação entre outros) e os parâmetros do rebolo são: dureza, tamanho dos grãos, tipo de abrasivo e o tipo de ligante [3].

Neste estudo, o objetivo foi o de analisar os cavacos metálicos removidos dos cilindros, após retificação e as partículas abrasivas de dois tipos diferentes de rebolo

* Contribuição técnica ao $51^{\circ}$ Seminário de Laminação - Processos e Produtos Laminados e Revestidos, 28 a 31 de outubro de 2014, Foz do Iguaçu, PR, Brasil. 


\section{$\underset{\text { Lolling }}{\text { LAMÇÃO }}$

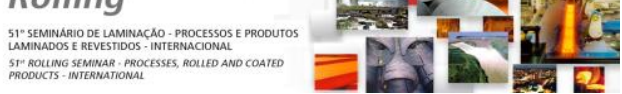

por meio de uma análise micrográfica. Em paralelo, o acompanhamento do desempenho dos rebolos foi decisivo na escolha do melhor rebolo, reduzindo o tempo e o custo de retificação.

A figura 2 a mostra uma imagem da retifica de cilindros em funcionamento, eliminando a superfície desgastada de um cilindro. Na figura 2b, é apresentada uma imagem ilustrativa do rebolo utilizado na máquina.

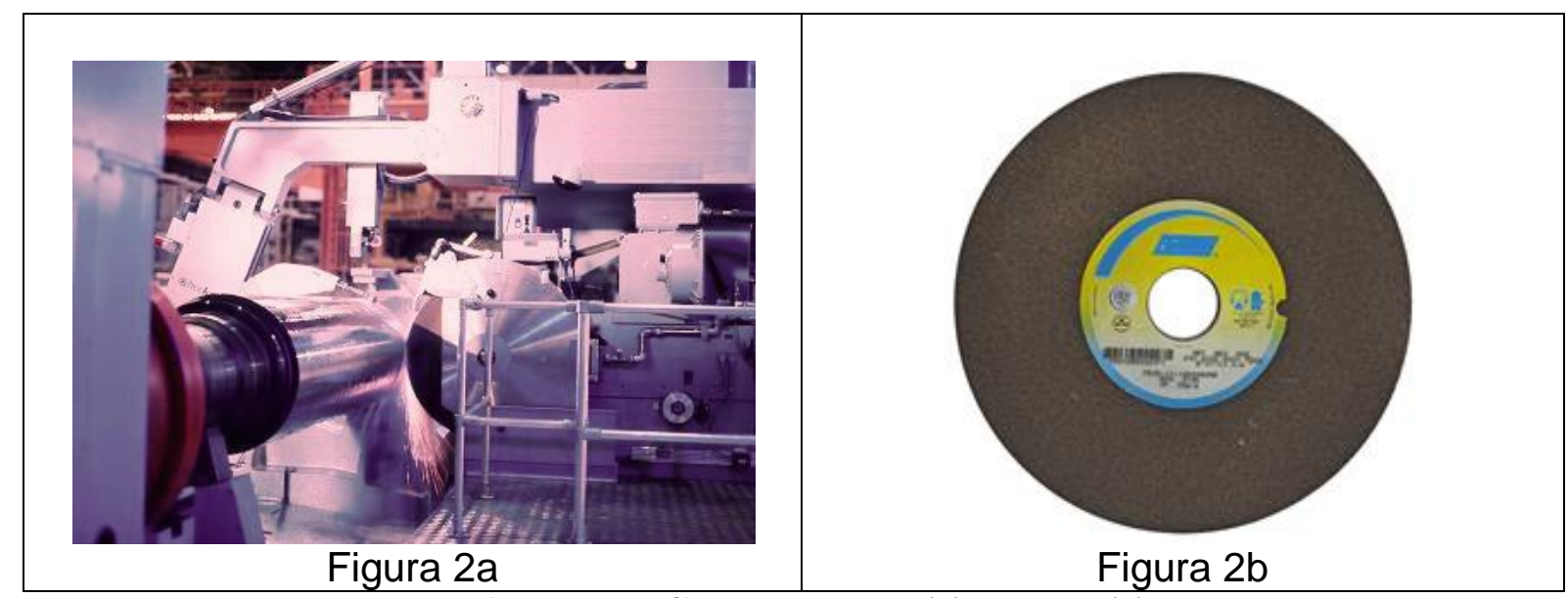

Figura 2: Retífica de cilindros (a) e rebolo (b).

As amostras utilizadas para a análise dos resíduos do rebolo no microscópio foram retiradas de dois tipos diferentes de rebolo e, definidas como rebolo $A$ (com duas amostras 01 e 02) e rebolo B (com duas amostras 03 e 04). Na figura 3, são apresentadas as imagens das quatro amostras do material coletado após o processo de retifica de cilindros.

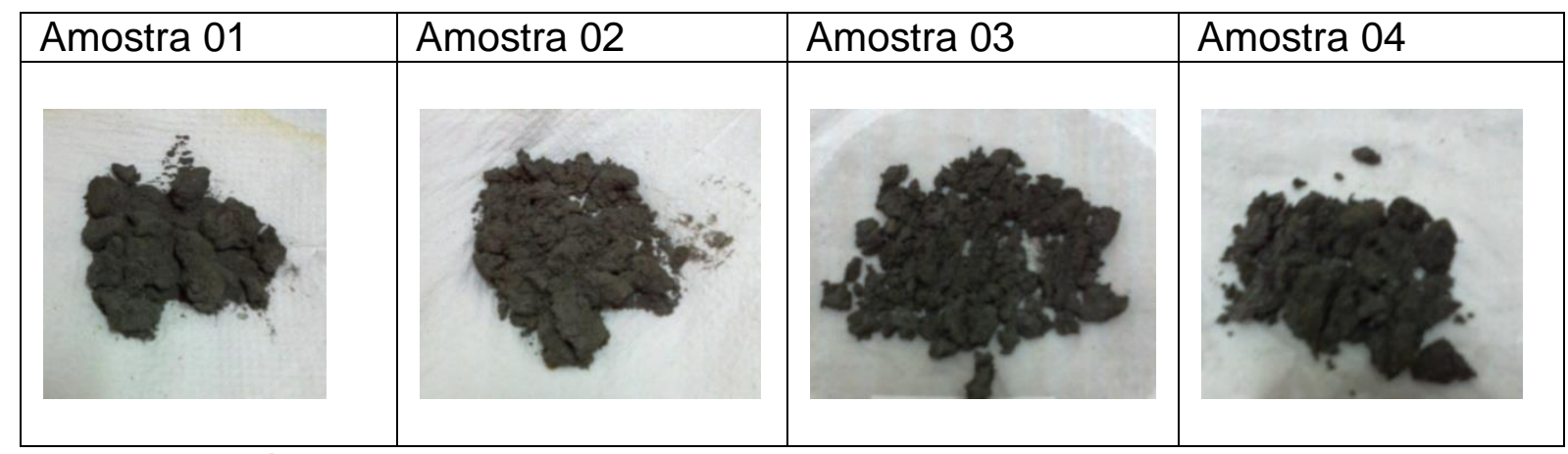

Figura 3 - Amostras 01 e 02 do rebolo A. Amostras 03 e 04 do rebolo B.

\section{MATERIAIS E MÉTODOS}

Desgaste abrasivo

A abrasão é uma das formas de desgaste que normalmente produz altas taxas de desgaste. Os mecanismos de desgaste à abrasão não é único e sim representa o tipo comum de dano com base em diferentes mecanismos físicos ou ações destrutivas de materiais. Isso depende dos materiais e suas propriedades, bem como a dinâmica dos contatos. Normalmente, a abrasão está associada a ação de diversas partículas duras em materiais mais macios [4].

Propriedades dos grãos abrasivos

Em um modelo simples de desgaste abrasivo desenvolvido anteriormente, as diferenças nos abrasivos eram consideradas como constantes e alguns casos

* Contribuição técnica ao $51^{\circ}$ Seminário de Laminação - Processos e Produtos Laminados e Revestidos, 28 a 31 de outubro de 2014, Foz do Iguaçu, PR, Brasil. 


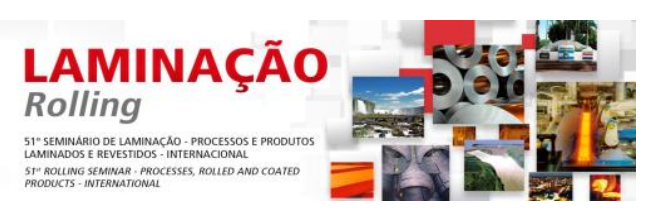

ignoradas. No entanto, a alteração do abrasivo vai mudar a taxa de desgaste. $\mathrm{O}$ efeito do ângulo crítico que, já discutido, e outras características abrasivas também irão contribuir. Entre estes estão a dureza, a tenacidade, e o tamanho do elemento abrasivo. Como a dureza do abrasivo excede a dureza do material, ele é capaz de penetrar na superfície de corte e, remover o material, sem ter suas arestas de corte arredondadas ou quebradas. A figura 4 mostra a dureza de minerais típicos e algumas ligas [5].

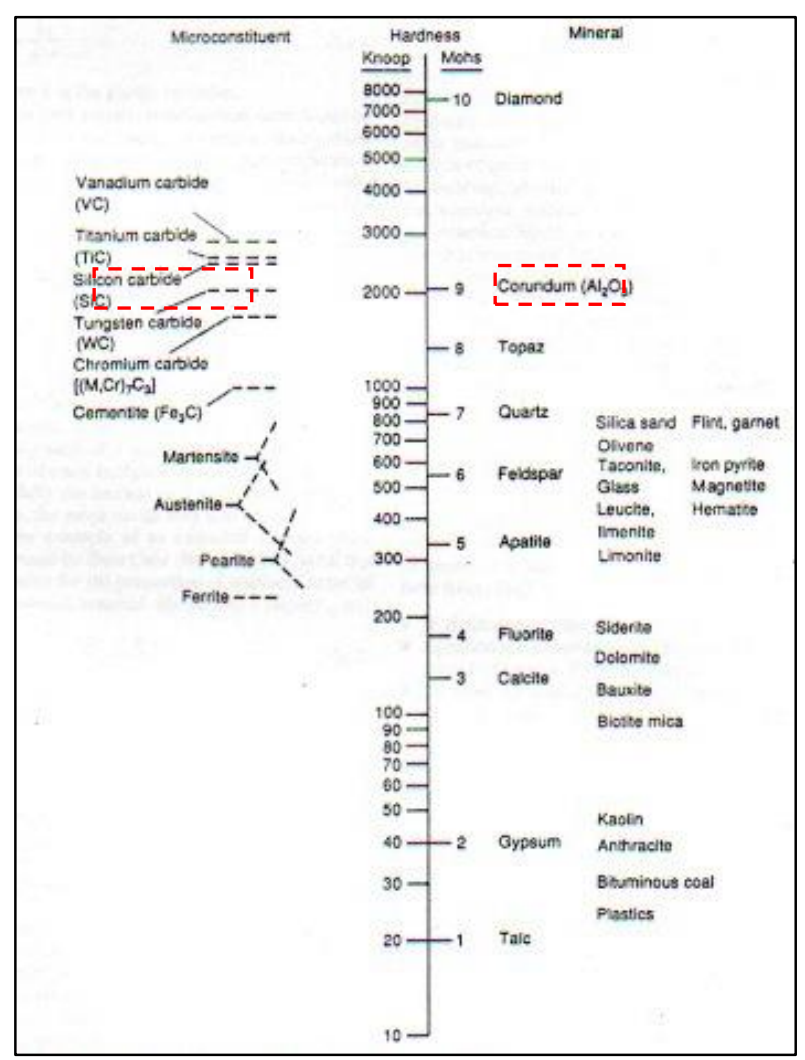

Figura 4 - Dureza de alguns materiais e ligas

A morfologia da partícula abrasiva é muito importante, uma vez que influencia a forma do "sulco" produzido no material. Também influencia a carga de contato e a transição de contato elástico para contato plástico. As experiências anteriores confirmam que o desgaste é menor quando os materiais são desgastados por partículas arredondadas, em vez de "afiado". [5]

A literatura refere também que o tamanho do abrasivo tem uma relação linear com a perda de peso, o coeficiente de atrito e a energia específica de corte para abrasivos pequenos. Depois de atingir um tamanho crítico de abrasivo, este apresenta uma alteração na inclinação ou comportamento heterogêneo. Para abrasivos pequenos, a taxa de desgaste aumenta proporcionalmente com o aumento do tamanho da partícula de abrasivo para atingir o tamanho crítico do abrasivo. Este fenômeno é apresentado no desgaste abrasivo a dois corpos, desgaste abrasivo a três corpos, erosão e desgaste abrasivo pelo processo de corte. [6]

Abrasivos devem suportar muitas solicitações. Dureza, resistência ao calor e fiabilidade são as principais propriedades. Quatro tipos básicos de abrasivo são usados, todos sintéticos. Todos eles atendem às diferentes necessidades em diferentes graus. Suas propriedades variam a cada grupo e a sua própria área especial de uso. A sintonia fina com combinações pode ser recomendada dentro de cada grupo para otimizar suas propriedades no processo de retifica. Em geral

* Contribuição técnica ao $51^{\circ}$ Seminário de Laminação - Processos e Produtos Laminados e Revestidos, 28 a 31 de outubro de 2014, Foz do Iguaçu, PR, Brasil. 


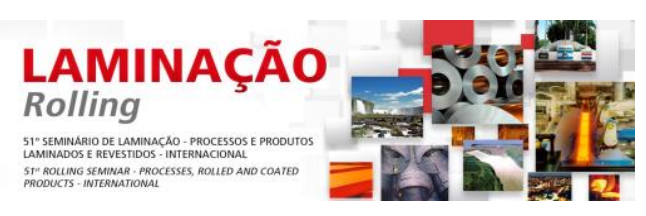

elevado grau de pureza do material reflete em estruturas muito homogêneas, mas os métodos de produção devido micro trincas estão sempre presentes. Como um resultado, esta quebra de material em fragmentos relativamente grandes, se dá sob carga. Um produto com um pequeno teor de cromo ou titânio dá ao abrasivo uma propriedade mais robusta que torna os rebolos mais duros. Friabilidade é a capacidade de rachar ou quebrar em pequenas frações, quando sob carga. Estão sendo muito desenvolvidas introduções de cerâmica (micro-cristalinas) como abrasivos. Exemplos destes são cubitron e cerpass. Na retificação de alta pressão bauxita sinterizada tem apresentado melhorias semelhantes nesta aplicação. É muito importante ter os abrasivos e elementos ligantes uniformemente distribuídos no rebolo. Isso dará um desempenho consistente de rebolo a rebolo no processo operacional.

\section{1 Óxido de Alumínio}

O óxido de alumínio (alumina ou $\mathrm{Al}_{2} \mathrm{O}_{3}$ ), internacionalmente designada pela letra $\mathrm{A}$, é, na maioria dos casos, o abrasivo mais adequado para todos os tipos de retificação de aço endurecido ou não endurecido. Se difere dos outros abrasivos em suas propriedades como dureza - tenacidade para atender às diferentes operações e materiais. Ele tem uma gama muito universal de uso; que faz com que seja o mais importante abrasivo.

Óxido de alumínio branco é fundido a partir de alumínio Bayer de alta qualidade em altas temperaturas. Sua dureza é maior, mas tenacidade menor em comparação com óxido de alumínio marrom.

É caracterizado por alta pureza, excelente auto- afiação, eficiência de retificação, e baixo calor de atrito. Ele pode suportar ácido e erosão alcalina, com resistência a altas temperaturas e boa estabilidade térmica.

As ferramentas abrasivas feitas dele são adequados para retificação de aço alto carbono, aço rápido e aço ligado. Ele também pode ser usado para lapidação e polimento médio, materiais de revestimento, cerâmicas especiais e materiais super refratários. (Veja figura 5a) [7].

Óxido de alumínio marrom é feito a partir de bauxita de alta qualidade. Fundido a uma temperatura elevada, superior a $2000^{\circ} \mathrm{C}$. Caracteriza-se com estrutura densa, grande dureza, auto afiação e excelentes propriedades de retificação, e baixa propriedade magnética. É apropriado para a fabricação de ferramentas ligadas, para lapidação, polimento e jateamento. Também é amplamente utilizado para refratários, aditivos químicos, fundição precisa e materiais anti-derrapantes. (Veja figura 5b) [7].

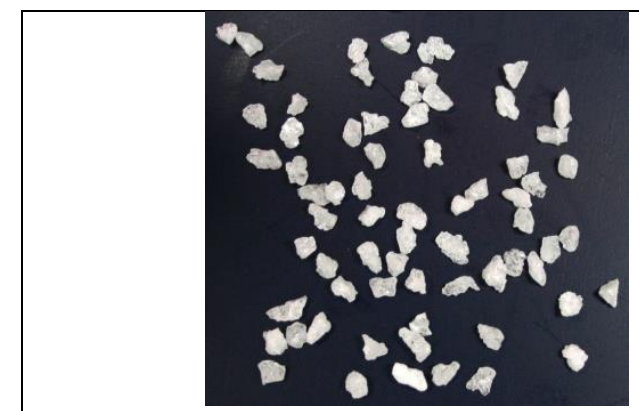

Figura $5 a$

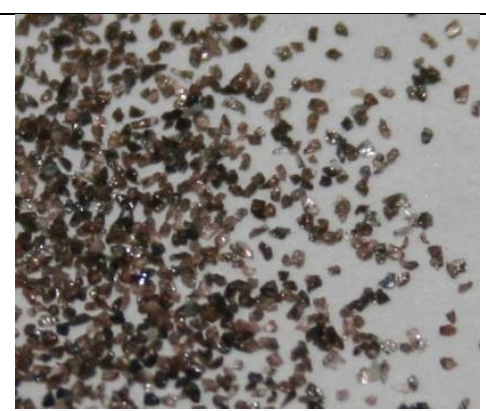

Figura $5 b$

Figura 5 - Partículas de alumina branca (5a) e partículas de alumina marrom (5b).

* Contribuição técnica ao $51^{\circ}$ Seminário de Laminação - Processos e Produtos Laminados e Revestidos, 28 a 31 de outubro de 2014, Foz do Iguaçu, PR, Brasil. 


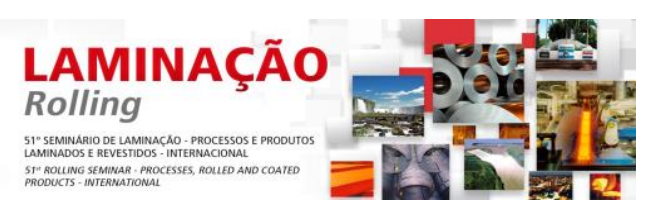

\subsection{Carbeto de Silício}

Carbeto de silício ( $\mathrm{SiC}$ ), é mais duro e mais friável do que Al2O3 e tem uma forma grão mais nítida. É menos universal nas aplicações que $\mathrm{Al} 2 \mathrm{O} 3$, devido às suas propriedades químicas, mas funciona bem em sua área especial.

Carbeto de silício negro é produzido a partir de areia e coque ou carvão como principal matéria-prima, derretido em alta temperatura em forno elétrico a arco. A sua dureza é entre alumina fundida e diamante sintético, enquanto que propiedades mecánicas é maior do que alumina fundida. É frágil e "afiado". Os abrasivos feitos dele são adequados para trabalhar em ferro fundido, metais não ferrosos, pedra, couro, borracha, etc. É também amplamente utilizado como material refratário e aditivo metalúrgico . (Veja figura 6a) [7].

Carbeto de silício verde é produzida da mesma maneira como o carbeto de silício preto, exceto em algumas diferenças na matéria-prima. A sua cristalização tem uma pureza mais elevada e maior dureza.

Carbeto de silício verde é adequado para o processamento de ligas duras, materiais metálicos e não-metálicos (como o cobre, latão, alumínio, magnésio, jóia, vidro ótico, cerâmica, etc.) apresenta propiedades de serem duros e quebradiços, (Veja figura 6b) [7].

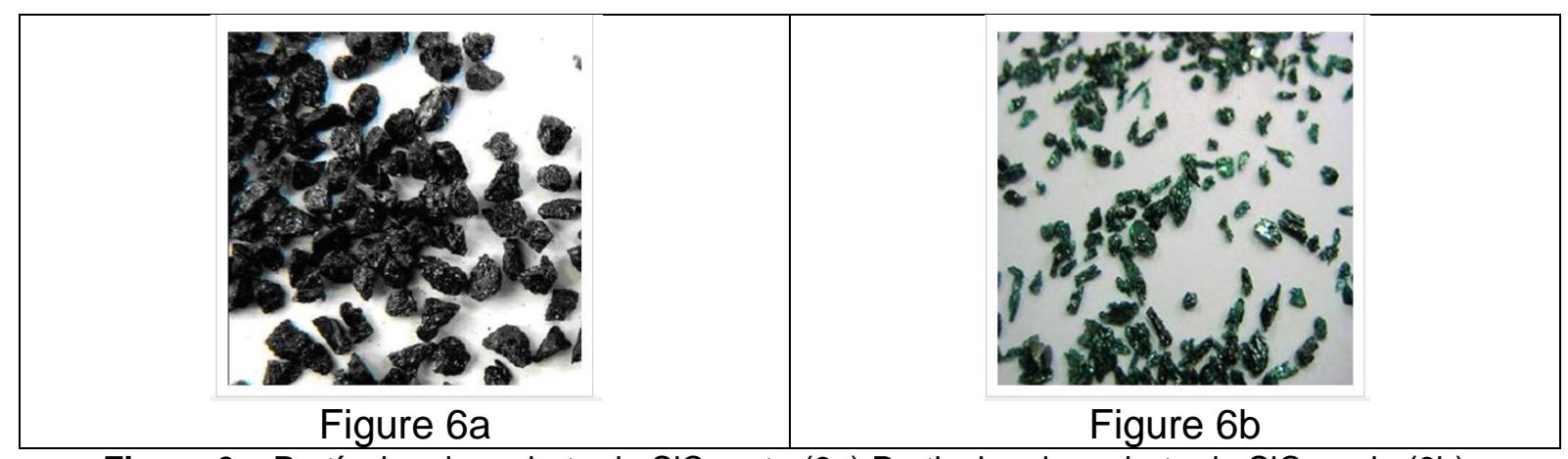

Figure 6 - Partículas de carbeto de SiC preto (6a) Particulas de carbeto de SiC verde (6b).

\subsection{Tipos de Rebolos Analisados}

Neste estudo, as partículas abrasivas e os fragmentos resultantes do processo de retifica para dois tipos diferentes de rebolos foram utilizadas na mesma máquina e foram analisados com os mesmos parâmetros de corte. Além disso, no caso de cilindros de laminação, não foram alteradas as qualidades e todos eles têm a dureza em torno de $75 \mathrm{SHC}$ feitos em ferro fundido nodular com coquilhamento indefinido (ICDP).

A rebolo definido como rebolo $\mathrm{A}$, consiste de partículas abrasivas alongadas de carboneto de silício preto e óxido de alumínio (monocristalino com formação intermediária entre o branco e o marrom), com tamanho de grão 46, em uma liga resinoide e dureza considerada baixa.

A rebolo definido como rebolo $\mathrm{B}$, consiste em carbeto de silício abrasivo com grão verde (criado em laboratório) e óxido de alumínio (cerâmico) com um tamanho de grão 46, em uma liga resinoide e dureza considerada baixa.

Uma vez conhecidos o rebolo e o material dos cilindros, foram coletadas amostras de resíduo do processo de retifica. As duas amostras do rebolo $A$ e $B$ foram então obtidas. Estas amostras foram colocadas em pratos sobre uma superfície absorvente e todo o líquido foi absorvido e evaporado conseguindo amostras secas.

* Contribuição técnica ao $51^{\circ}$ Seminário de Laminação - Processos e Produtos Laminados e Revestidos, 28 a 31 de outubro de 2014, Foz do Iguaçu, PR, Brasil. 


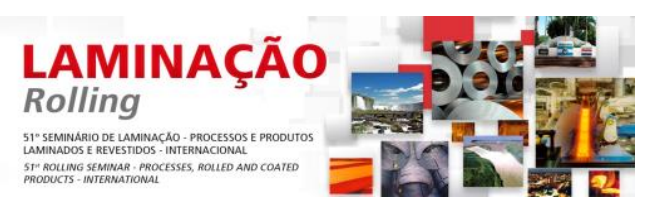

Coletadas e identificadas, foram submetidos a análise microscópica através de microscópio eletrônico de varredura TESCAN VEJA 3 com sistema EDS OXFORD.

Foram então, definidas três diferentes aumentos com 200X, 500X e 1000X para as amostras coletadas.

Posteriormente, a fim de identificar corretamente os elementos abrasivos que compõem as amostras, foi utilizado o recurso SEM EDS, criando gráficos de composição química de cada partícula analisada.

\section{RESULTADOS E DISCUSSÃO}

Os ensaios realizados com o MEV permitiram uma análise da morfologia dos cavacos de ferro fundido dos cilindros e um comparativo do efeito de cada um dos rebolos, A e B após o processo de retifica.

As imagens foram também capazes de mostrar a morfologia dos elementos abrasivos, após o processo de retifica. E, finalmente, com a utilização de uma SEM EDS, identificar com maior precisão a composição química de cada partícula.

\subsection{Resultados com Rebolo A}

As imagens obtidas a partir da amostra 01 (S1), referindo-se ao rebolo A após retificação, permitiu verificar o tamanho e a forma dos cavacos de ferro fundido dos cilindros, conforme a figura 7, com os aumentos de 200X, 500X e 1000X.

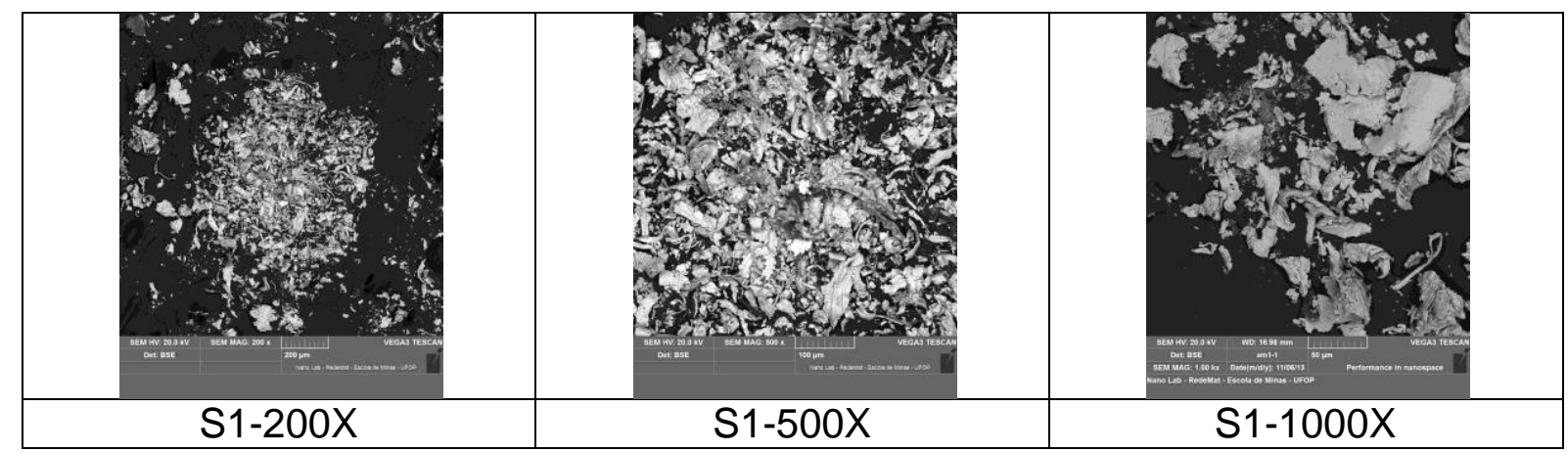

Figura 7 - Amostras dos cavacos de ferro fundido.

No caso da amostra 02 (S2), relativa ao rebolo $A$, foi objetivado obter imagens dos elementos abrasivos e, neste caso, as partículas de $\mathrm{Al}_{2} \mathrm{O}_{3}$, conforme figura 8 aumenta com aumentos de 200X, 500X e 1000X.

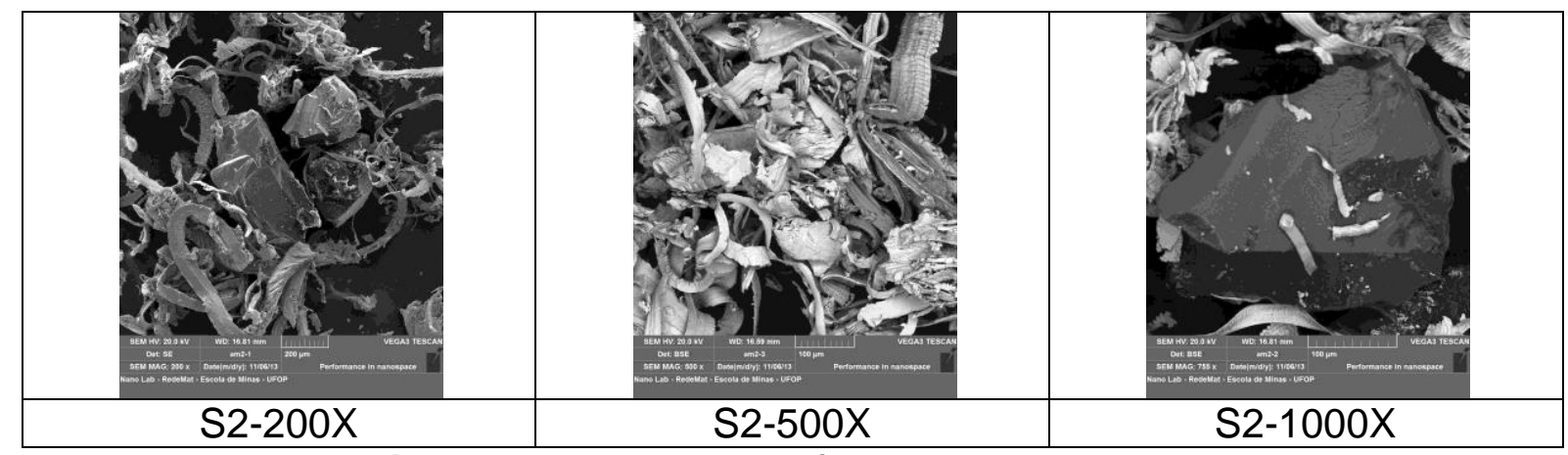

Figura 8 - Amostras das partículas abrasivas do rebolo A.

* Contribuição técnica ao $51^{\circ}$ Seminário de Laminação - Processos e Produtos Laminados e Revestidos, 28 a 31 de outubro de 2014, Foz do Iguaçu, PR, Brasil. 


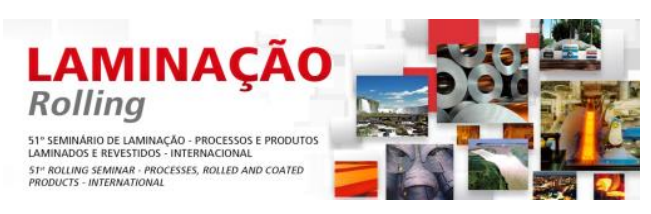

De forma a confirmarmos a composição exata das partículas abrasivas analisadas, utilizamos o recurso EDS do microscópio e obtivemos os gráficos conforme figura 9 , para as amostras 01 e 02 respectivamente.
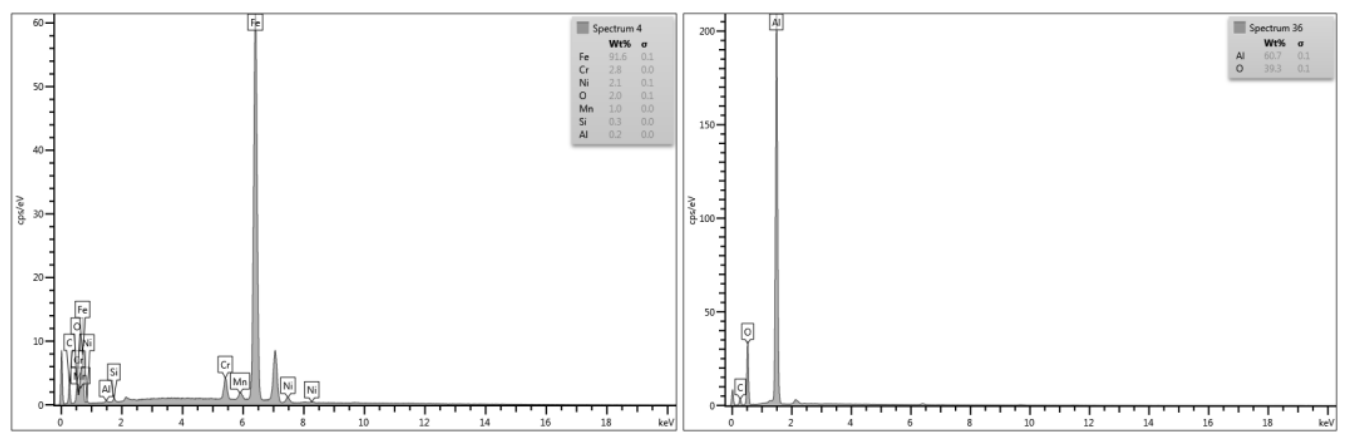

Figura 9 - Cavacos de ferro fundido (amostra 01) e, partícula de alumina (amostra 02).

\subsection{Resultados com o Rebolo B}

As imagens obtidas a partir da amostra 03 (S3), para a rebolo $B$, permitiu verificar 0 tamanho e a forma dos cavacos de ferro fundido dos cilindros, após o processo de retifica, conforme figura 10 , com os aumentos de $200 \mathrm{X}, 500 \mathrm{X}$ e $1000 \mathrm{X}$.

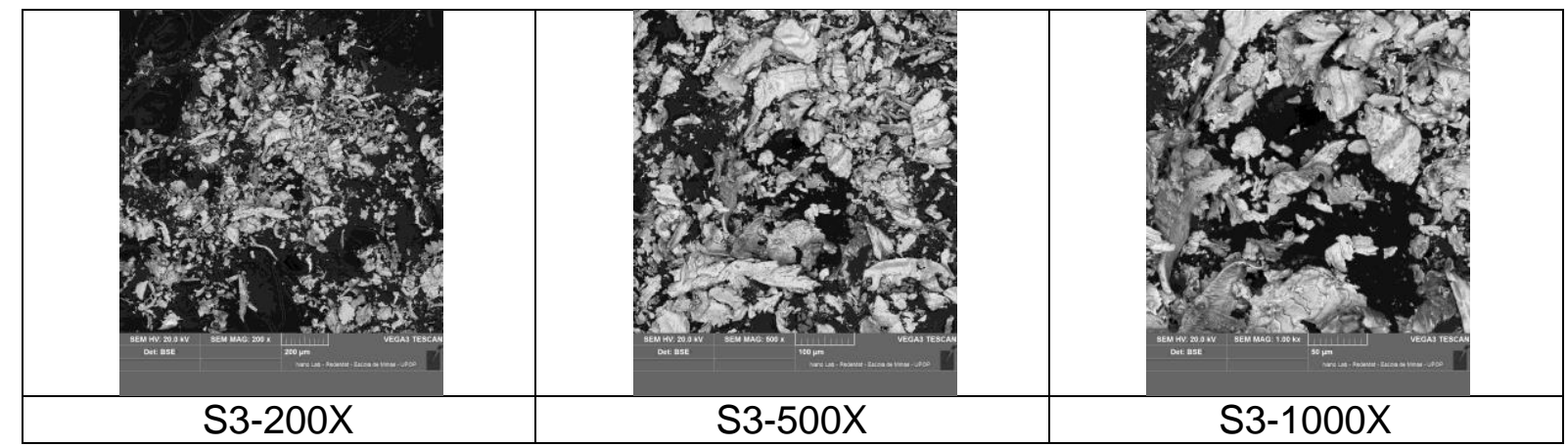

Figure 10 - Amostras dos cavacos de ferro fundido.

No caso da amostra 04 (S4) foi objetivado obter imagens dos elementos abrasivos e, neste caso, as partículas abrasivas de carbeto de silício e $\mathrm{Al}_{2} \mathrm{O}_{3}$, como pode ser visto na figura $11 \mathrm{com}$ aumentos de 200X, 500X e 1000X.

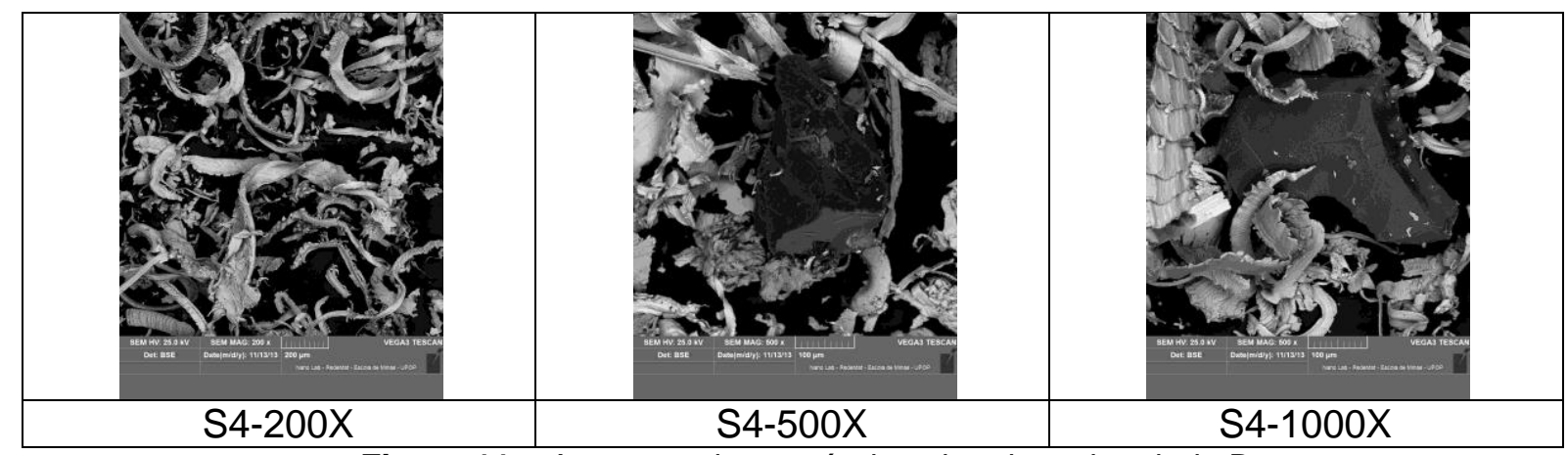

Figure 11 - Amostras das partículas abrasivas do rebolo $\mathrm{B}$.

Da mesma forma usada anteriormente, confirmamos a composição exata das partículas abrasivas analisadas, utilizando o recurso EDS do microscópio e

* Contribuição técnica ao $51^{\circ}$ Seminário de Laminação - Processos e Produtos Laminados e Revestidos, 28 a 31 de outubro de 2014, Foz do Iguaçu, PR, Brasil. 


\section{$\underset{\text { Rolling }}{\text { LMINAC̄̃O }}$

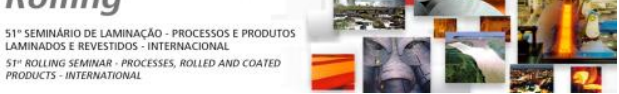

obtivemos os gráficos conforme figura 12, para as amostras 03 e 04 respectivamente.
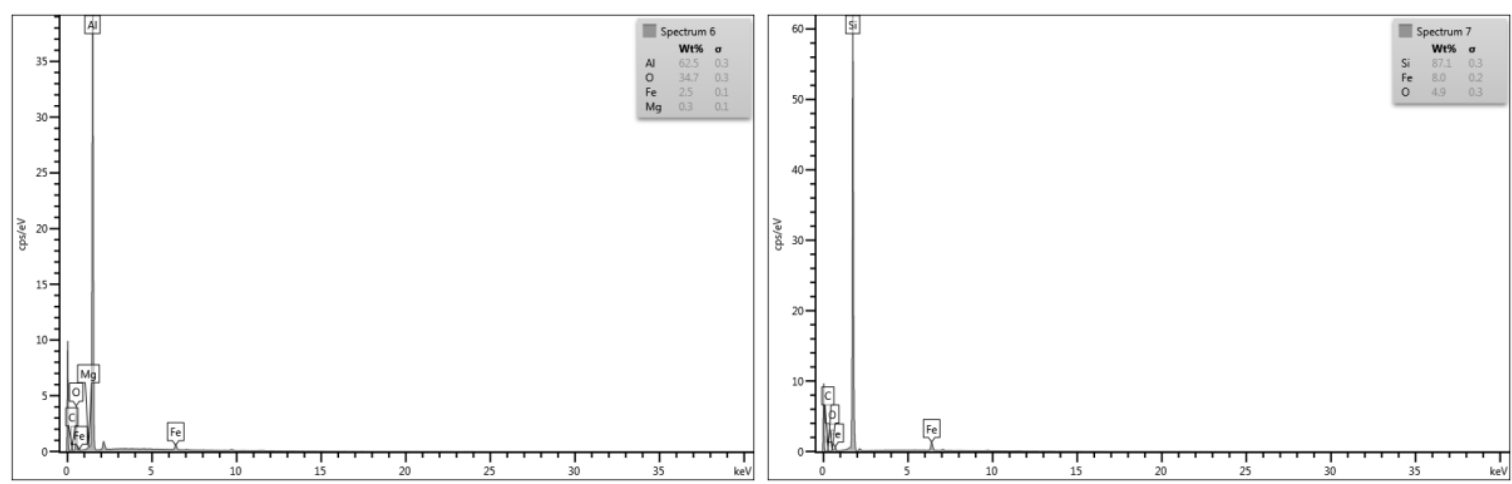

Figura 12 - Partícula de alumina (amostra 03) e, partícula de SiC (amostra 04).

\subsection{Resultados de Desempenho dos Rebolos}

Concluída toda etapa de testes com caracterização microscópica, foram coletadas as informações de retificação de cilindros que forneceram os dados de consumo em milímetros de rebolo e de consumo de $\mathrm{mm}$ de cilindros.

Estes valores correspondem a cada um dos rebolos em questão, o rebolo $A$ (amostra 1 e 2) e rebolo B (amostra 3 e 4). O desempenho é medido pela razão de $\mathrm{mm}$ consumidos de rebolos por $\mathrm{mm}$ de cilindros removidos e, os resultados podem ser observados no gráfico da Figura 13.

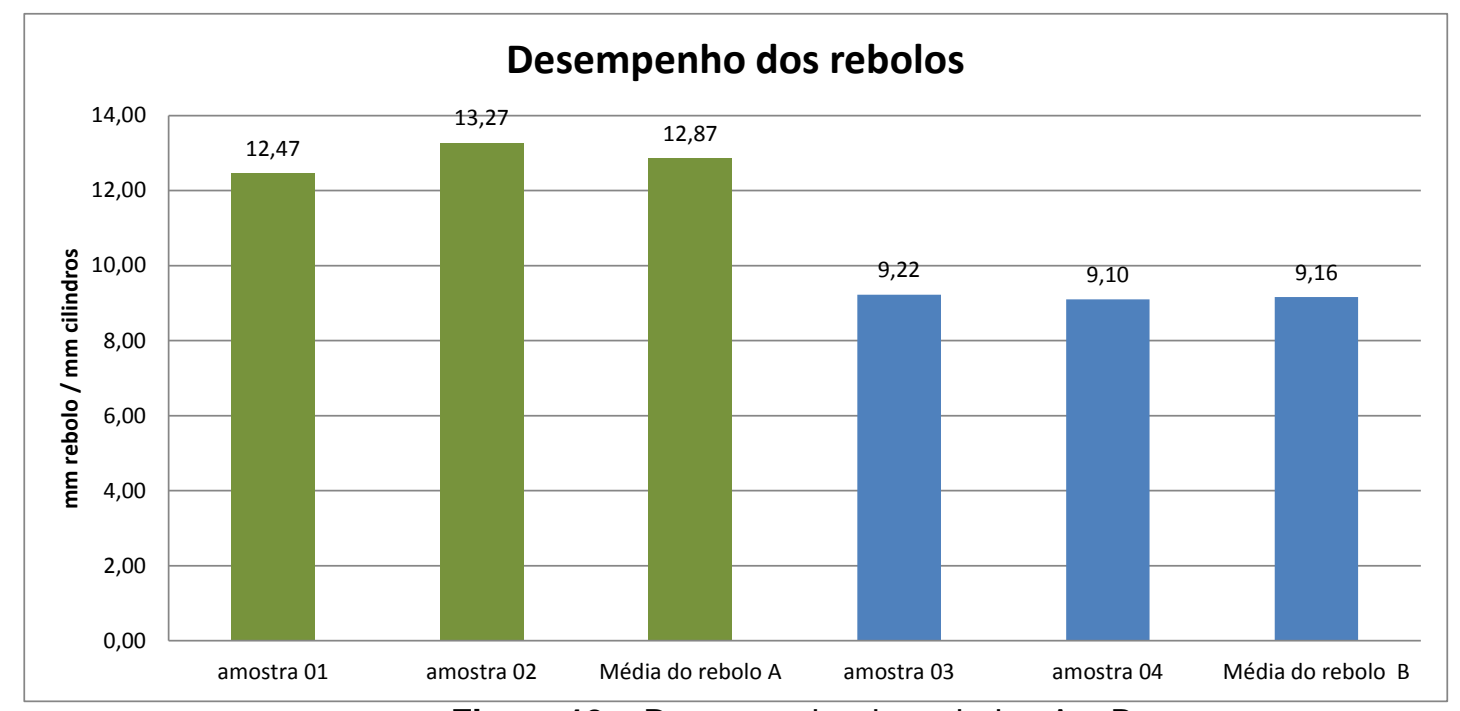

Figure 13 - Desempenho dos rebolos A e B.

\section{CONCLUSÃO}

Foi obtida uma redução de $28,8 \%$ no consumo de rebolo utilizando o rebolo $B$ em comparação ao rebolo $A$.

O tamanho do grão abrasivo não teve nenhuma influência significativa sobre a taxa de remoção devido aos dois tipos de rebolos $(A)$ e $(B)$ tendo um tamanho médio de grão de 46.

* Contribuição técnica ao $51^{\circ}$ Seminário de Laminação - Processos e Produtos Laminados e Revestidos, 28 a 31 de outubro de 2014, Foz do Iguaçu, PR, Brasil. 


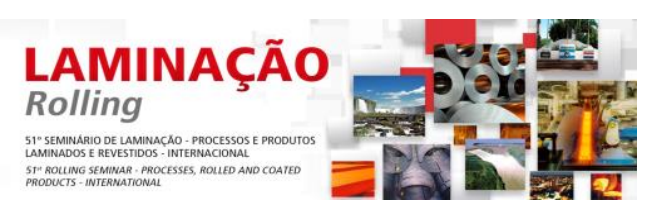

No caso das ligas resinóides, como foi utilizada a mesma composição, também não foi observada grande influência sobre a taxa de remoção, especialmente na adesão das partículas abrasivas nos rebolos.

A morfologia do abrasivo, após o processo de retifica, não foi alterada, tanto para o rebolo $(A)$ ou $(B)$.

Em termos de rugosidade da superfície dos cilindros, após o processo de retificação, não foram evidenciadas grandes variações na medida para dois tipos de rebolos.

A morfologia dos cavacos metálicos removidos a partir do cilindro e, identificado por EDS mostrou muito semelhante para ambos cortes com os dois tipos de rebolos utilizados.

O principal fator de eficiência do rebolo $(B)$ em relação ao rebolo $(A)$ é a quantidade de material removido por passe/corte no processo de retifica, ou a taxa de remoção de material metálico.

\section{REFERÊNCIAS}

1 Kato K, Adachi K. Wear Mechanisms, Modern Tribology Handbook, Ed. CRC Press LLC, 2001 Vol. 2 Cap22.

2 Paiva JC, Campbell LAP, Erbiste MO, Nascimento ND, Camacho EF. Desenvolvimento de rebolo para retificação de cilindros do laminador de tiras a quente da CSN. In Associação Brasileira de Metalurgia, Materiais e Mineração. Anais do $44^{\circ}$ Seminário de Laminação, Processos e Produtos Laminados e Revestidos; 2007; Campos do Jordão, SP, Brasil. São Paulo: ABM; 2007.

3 Slip Naxos, Winterthur Technology Group, Roll grinding handbook: www.winterthurtechnology.com

4 Basu B, Kain M. Tribology of ceramics and Composites: A materials Science Perspective, First Edition. 2011 The American Ceramic Society.

5 ASM (American Society for Metals. Friction, lubrification and wear technology. In: Metals Handbook, Vol. 18, 1992.

6 Marin JJC. Efeito do tamanho do abrasivo no desgaste de metais. Ed. Ver. São Paulo, 2010. Tese (Doutorado) Escola Politécnica da Universidade de São Paulo.

Departamento de Engenharia Mecânica.

7 Harmony Abrasives [página da internet]. P.R.China. Disponível em:

http://www.abrasives.com.cn/en/index.html

* Contribuição técnica ao $51^{\circ}$ Seminário de Laminação - Processos e Produtos Laminados e Revestidos, 28 a 31 de outubro de 2014, Foz do Iguaçu, PR, Brasil. 